\title{
TOWARDS A FRAMEWORK OF THE SUB- DISCIPLINES OF PRODUCT DESIGN TO ENABLE APPROPRIATE COURSE SELECTION FOR PROSPECTIVE STUDENTS
}

\author{
Paul RUSSELL and Lyndon BUCK \\ Buckinghamshire New University, United Kingdom
}

\begin{abstract}
Variants of the discipline most commonly known as 'Product Design' are taught in over 80 undergraduate degrees at over 50 universities in the UK. There is an incredibly wide scope between the types of products, teaching content and approach to designing products between them due to the diversity of products required and/or desired by consumers. Some courses are closer to Applied Arts and the Crafts, and others are closer to Engineering and the embodiment of new technology, with the rest lying somewhere between those two extents. However, the majority of courses in the UK use the increasingly nondescript title of 'Product Design' which does not enable students to easily differentiate between them by course title alone. The use of different course designations (e.g. BA/BDes/BSc/BEng) are used by many universities to add more clarity to the priorities and approach of their course/s but there is no agreed framework which is in use that ensures consistency in the use of different designations between universities. Furthermore, where variants of the title 'Product Design' are used, they are also used inconsistently; even, in the case of 'Industrial Design', being at opposite ends of the aforementioned scale. These inconsistencies and contradictions add unnecessary complication for prospective students when seeking a higher education course on which to study. A framework of designations and degree titles could enable prospective students to more effectively filter courses to those which better align with their qualifications, abilities and interests, and simplify things for them at what can be an already unsettling and stressful time.
\end{abstract}

Keywords: Design education, design engineering, industrial design, engineering design

\section{INTRODUCTION}

"Design ... means so many different things that it almost doesn't mean anything", Joichi Ito wrote in 2016 [1], concurring with similar comments made by a number of other practitioners and researchers over the last fifty years. However, the same can be increasingly said about the use of 'Product Design' as the title of a discipline or as a profession and this can cause unnecessary complexity in course selection for prospective students. To put into perspective the scope of use of 'Product Design' as a title for degree courses in the UK; it is the only field of study in which you can undertake a degree in more than two designations (i.e. BA or BSc). In the UK it is possible to undertake a degree in 'Product Design' in no less than four designations; in Art (BA/MA), in Design (BDes/MDes), in Science (BSc/MSc), and also in Engineering (BEng/MEng) [2]. However, there is no universally adopted distinction between the different designations which is used among different universities so is often not possible for students to have a sufficient idea of what a course entails from the course title and designation alone.

Some universities use variations of 'Product Design' in an attempt to add more clarity, with 'Design Crafts', 'Industrial Design', 'Product Design Engineering', and 'Engineering Product Design' being the most commonly used [2], but these are also used inconsistently between different universities. As an example to demonstrate this point; 'Industrial Design' at a number of universities in the UK is a Bachelor of Arts with a less technical focus than a Bachelor of Science in 'Product Design' at the same universities, but 'Industrial Design' at an equal number of other universities is a Bachelor of Engineering degree with a much greater focus on technical and engineering content than the BA 'Industrial Design' degrees at the first group of universities. Thus, neither designation nor course title can be used by prospective students to quickly filter courses to those which are suitable to their qualifications, abilities 
and interests in relation to designing products. The purpose of the research undertaken in this paper is to produce a framework which could be adopted by universities in the UK to make appropriate course selection clearer and easier for prospective students.

The concept presented in this paper has emerged from research being undertaken by the primary author which is looking into the role of designing products which contribute to the alleviation of poverty in the developing world. When trying to communicate the role that Product Design has in poverty alleviation efforts it immediately becomes apparent that formally defining Product Design is first required. In the context of products designed for impoverished communities it then becomes apparent that trying to define 'Product Design' as a singular discipline which is involved with the design of physical products is insufficient to answer the question because of the breadth and scope of designed products. Several approaches to the design of products across the spectrum presented in this paper are in use in poverty alleviation efforts today, each with their benefits and limitations. Only by discussing 'Product Design' in the holistic way presented in this paper can the breadth and scope of the value and impact of designed products be communicated thoroughly. The question of its relation to design education and employment emerged out of this research and has been pursued as a line of enquiry with academics, practitioners and students which is presented in this paper.

\section{DEFINING PRODUCT DESIGN}

'Product Design' is the act of undertaking the design of products as a professional occupation. However, both the terms 'Design' and 'products' need clarification as they are both increasingly used in disparate ways. 'Products' as used in this context is not the definition meaning 'the result of an action or process', which could be used to describe the outcomes of any of the Design fields, but more specifically "something that is made to be sold, usually something that is produced by an industrial process" [3]. It is this specific descriptor; that 'Product Design' as a profession is involved with the creation of physical, tangible and manufactured artefacts, and at scale, which has typically defined it and differentiated it from the other Design professions (e.g. Graphic Design, Service Design, etc.).

'Design', as used in this paper, is taken to mean the synthesis of knowledge (processed, objective data) and intuition (a combination of tacit knowledge and natural instinct) to devise novel artefacts which, if realised, would provide greater value than existing artefacts for at least one stakeholder. It is this need for a combination of both systematic and objective drivers (e.g. physics, ergonomics, costing) and the reflective and subjective drivers (e.g. form, colour, meaning) which define design as a distinct domain of knowledge; separate from pure Engineering, which is reliant only upon systematic ways of thinking, and pure Art, which is reliant only upon reflective and intuitive ways of thinking [4]. 'Product Design', in the UK, is typically considered to be as described in Figure 1 below where, on a scale of disciplines between the arts and crafts on one side and engineering and technology on the other, 'Product Design' is considered to be balanced equidistant between the two extents.

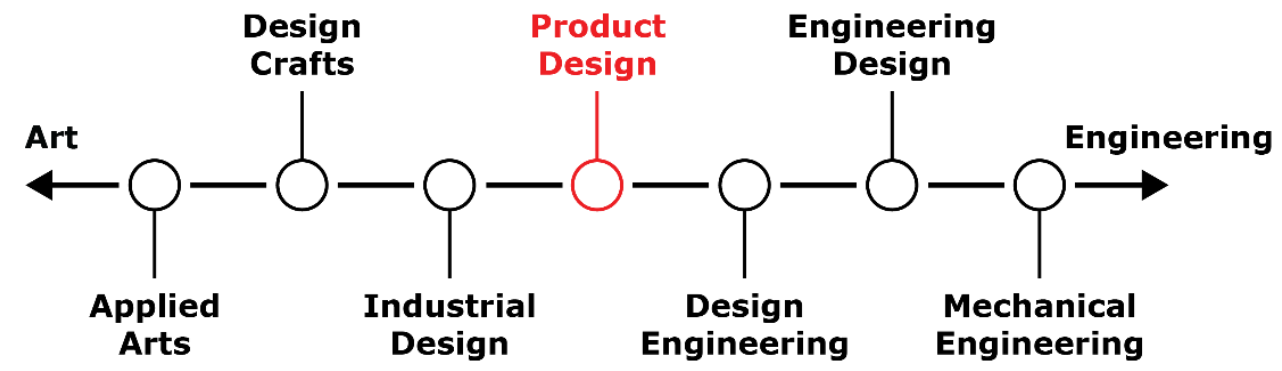

Figure 1. The disciplines involved with the devising of physical, tangible artefacts for sale; showing 'Product Design' as being a discipline which is balanced equally between the more artistic and more engineering driven disciplines.

It is important to note that the terms 'Product Design' and 'Industrial Design' are considered to be synonymous by some practitioners and researchers and not to be by others, and also that their usage depends on the county in question. 'Product Design' is a more common title in the UK, but Industrial Design is more common in the USA, Asia and Europe. However, the author of this paper agrees with the position that they are not synonymous, in line with the following distinction; 
“'Industrial design' mainly refers to a 'practice' in the entire 'design' domain, while 'product design' stands for 'a combination of practices'. Thus, 'product design' should be considered not as a 'discipline', but as an 'activity' consisting of the contribution of various disciplines. ' [5]

In this way, 'Industrial Design' can be considered to be one of the sub-disciplines of 'Product Design', along with the other disciplines (as taken from the most common course names in the UK and also the most common for job titles) which are concerned with the design of physical, tangible products that are manufactured at scale. Figure 2 below has been devised to demonstrate how 'Product Design' can be defined as a discipline made up of a number of sub-disciplines including 'Industrial Design'. Thus, for the purpose of the framework, 'Product Design' is considered to be defined as 'the collection of disciplines which are involved with designing physical products for sale', using the definitions of 'products' and 'design' as explained above.

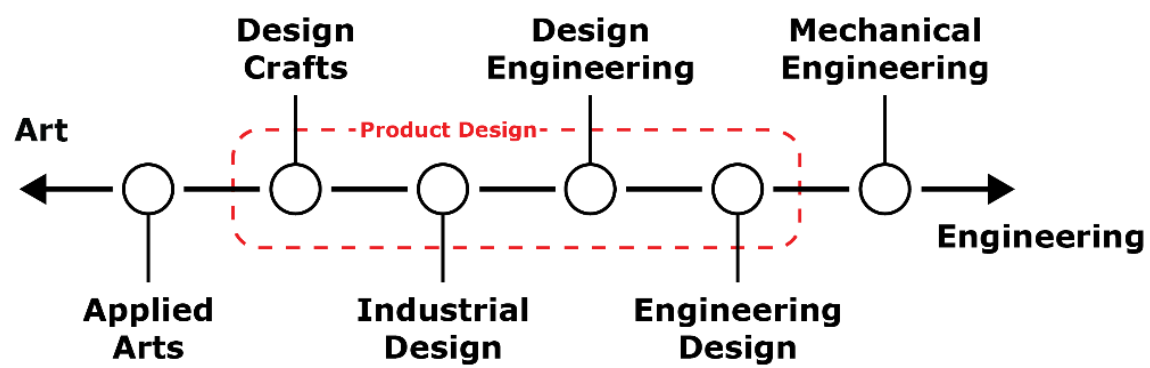

Figure 2. 'Product Design' as a discipline made up of a group of sub-disciplines which are involved with the design of physical, tangible products for sale that are manufactured at scale.

\subsection{The sub-disciplines of Product Design}

There have been a number of frameworks created in the last 70 years, since design theory and practice became subjects of research, which show how 'Industrial Design' and 'Engineering Design' relate to one another and to the disciplines of Art and Engineering [6][7], but none account for the newer disciplines of Design Engineering (working in the ground between the aforementioned disciplines) and Design Crafts (using more varied materials and manufacturing processes than pure crafts, utilising digital manufacturing methods, and being manufactured at larger scales). 'Industrial Design' and 'Engineering Design' both have well-established histories, having emerged at the end of the Second Industrial Revolution in $\sim 1880$, and are very well-defined in the literature so are not defined in more depth here. 'Design Engineering' and 'Design Crafts', as taught in degrees using the title today, are newer disciplines and are less well defined in the literature so are explained in more detail below to ensure clarity of how they are being defined in this paper and for the purpose of the model.

\subsubsection{Design Engineering}

The first reference to 'Design Engineering' can be found in John Dixon's 'Design engineering: Inventiveness, analysis, and decision making' from 1966 wherein he discusses it mostly in relation to Engineering Design [8]. Dixon positioned Design Engineering as being more concerned the roles which the humanities and the social sciences have in the design of products, as well as the use of the sciences of marketing, and of manufacturing and production, than Engineering Design. However, Design Engineering really emerged as a distinct discipline with a large body of practitioners in the late 2000s, with all of the books published which use the phrase 'Design Engineering' specifically in the title being published after 2010 [9][10]. These more recent works discuss Design Engineering in relation to Industrial Design and consider it to require more technical and engineering knowledge than it, as well as greater skills specifically in CAD and simulation (e.g. FEA and CFD). The discipline of Design Engineering thus lies neatly between Industrial Design and Engineering Design when considering the sub-disciplines of Product Design in terms of the skills and knowledge required to practice in this area and the approach taken to the design of products.

\subsubsection{Design Crafts}

'Design Crafts', as defined by the curriculum taught in degrees using this title today, is also fairly new and is without an entirely consistent definition in the literature or in course documentation from different universities. An amalgamation of 'Design' (as defined in the previous section above) and 'Crafts' where artefacts created by practitioners in the craft fields are typically undertaken at small scale and 
involve using only natural and vernacular materials (e.g. wood, clay, textiles, glass, stone, etc.). In difference to practitioners of pure crafts fields, practitioners of 'Design Crafts' use a wider variety of materials, including more modern, manmade materials such as polymers and elastomers, concrete, plywood, MDF and other manmade wood-based products. Design Crafts practitioners also make use of a wider variety of manufacturing processes than pure crafts practitioners, in particular because they make use of digital and automated manufacturing processes (specifically CNC machining for products and for moulds, CNC routing and laser cutting) whereas traditional Crafts practice is all done by hand or with basic, manually operated machinery.

\subsection{Differences between the sub-disciplines}

\subsubsection{Scales of manufacture}

The scale of manufacture for artefacts created by Design Crafts practitioners is higher than in pure Crafts practice or in 'Applied Arts' which are typically one-offs, being batch production in the hundreds at most, but are still much smaller than the scales of production of artefacts designed by Industrial Designers. Industrial Designers and Design Engineers typically undertake the design of products which are produced at mass production scale, with large variance in the quantity of products produced depending on the project at hand. Engineering Designers most often work on the design of components or products at continual production scales.

\subsubsection{Types of products designed}

Practitioners in the field of Design Crafts typically design products for categories including bespoke/batch produced furniture, homewares, kitchenware (non-electronic products), ceramics, ornaments, and toys made from natural materials. Some examples of the categories of products which Industrial Designers are typically involved with include mass-produced furniture, whitegoods, kitchenware (including electronics), consumer electronics, computing devices and packaging. Examples of the categories of products which Design Engineers are typically involved with include medical products, technology products, sports and gym equipment, urban furniture, building components, and garden products. Examples of products which are typically in the realm of work undertaken by Engineering Designers include automotive components and products, power tools, small-scale vehicles (e.g. quad bikes, snowmobiles, etc.) and anything which involves more complex simulation and verification before production.

\subsubsection{Knowledge and skills required}

Due to the different kinds of products which are typically produced by practitioners in the different subdisciplines and the different scales of manufacturing which are involved, the types, breadth and depth of different knowledge and skills required also differ. One way which this could be characterised is in the difference between the weighting that each sub-discipline has in their approach practice in terms of intuitive/reflective thinking and systematic/analytical thinking. It is clear that products which require more consideration for the use of engineering, such as medical products or vehicles, require more use of systematic and analytical ways of thinking and creating, whereas products that require more consideration for human emotions and interaction, such as wooden toys or ornaments, would require more reflective and intuitive ways of thinking and creating. These systematic/analytical, and reflective/intuitive ways of thinking and creating are inevitably reflected in the properties and values of the products which are designed using them. If these values and properties are then correlated back to the practices of the subdisciplines then the subdisciplines could be defined in terms of the differences in the weighting of each type of thinking and creating involved in practicing in said subdisciplines.

\section{PRODUCT VALUES AND THEIR RELATION TO PRACTICE IN THE DIFFERENT SUBDISCIPLINES OF PRODUCT DESIGN}

A number of researchers have related the values of products back to Abraham Maslow's 'hierarchy of needs' in recent years, with 'functionality' at the base and 'meaningfulness' at the peak [11]. However, mapping values in this way does not take into account the type of product being designed. An ornament does not need to have much, if any, consideration for functionality, whereas a car engine manifold does not need to have much, if any, consideration given to meaningfulness. A more useful way of mapping these values when discussing them in terms of how they relate to the sub-disciplines of Product Design 
could be where they lie on a scale from systematic to reflective types of thinking, as shown in Figure 3 below.

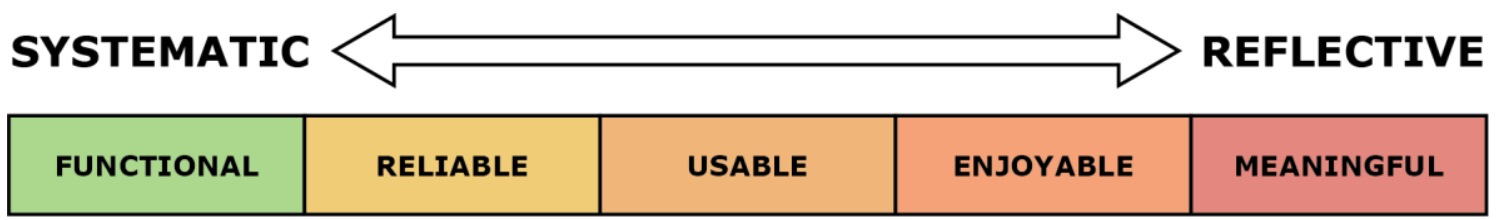

Figure 3. The values of products and how they relate on a scale between systematic and reflective practice.

The different sub-disciplines could then be categorised based on their weighting of focus between these values in how they generally approach to the design of products, which itself is heavily influenced by the kinds of products typically designed in each of them. In order to build up a model of how this could look a short survey with an introductory passage which explained what the study was seeking to describe was set up and distributed to be completed by academics, practitioners and students. The main question on the survey asked participants to quantify each of the values which can be used to describe a product up to a total of 10 points, with at least 1 point given to each of the values. 31 people responded to the survey; 6 academics, 7 practitioners and 18 students. The results of the survey are presented in Figure 4 below where the average weightings (points given by respondents, converted into percentages) are shown by sub-discipline.

\begin{tabular}{|c|c|c|c|c|c|}
\hline & \multicolumn{4}{|c|}{ Sub-Discipline of Product Design } \\
\hline & & $\begin{array}{l}\text { Design } \\
\text { Crafts }\end{array}$ & $\begin{array}{c}\text { Industrial } \\
\text { Design }\end{array}$ & $\begin{array}{c}\text { Design } \\
\text { Engineering }\end{array}$ & $\begin{array}{l}\text { Engineering } \\
\text { Design }\end{array}$ \\
\hline \multirow{5}{*}{ 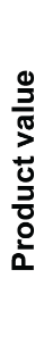 } & Meaningful & $30 \%$ & $20 \%$ & $10 \%$ & $10 \%$ \\
\hline & Enjoyable & $30 \%$ & $20 \%$ & $20 \%$ & $10 \%$ \\
\hline & Usable & $20 \%$ & $30 \%$ & $30 \%$ & $20 \%$ \\
\hline & Reliable & $10 \%$ & $20 \%$ & $20 \%$ & $30 \%$ \\
\hline & Functional & $10 \%$ & $10 \%$ & $20 \%$ & $30 \%$ \\
\hline
\end{tabular}

Figure 4. The results of respondents to the survey showing the averages (rounded up to the nearest 10) of the different weightings given to different product values by different sub-disciplines of Product Design.

It is interesting to note that the ratings are perfectly mirrored about the centre and that, because of this, rather than categorising the sub-disciplines rigidly they could instead be presented as being on a scale between majority reflective and systematic approaches to designing products (as shown in Figure 5).

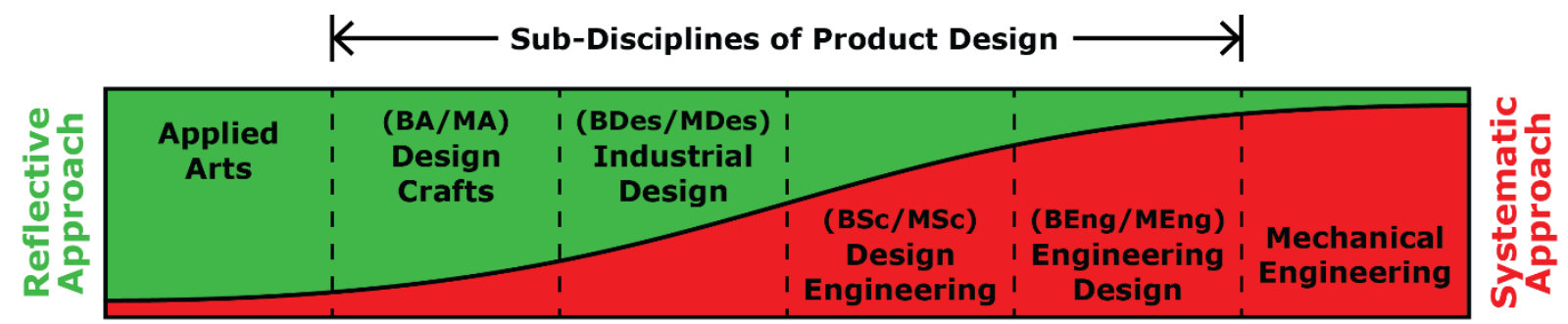

Figure 5. The sub-disciplines of Product Design on a scale showing the ratios between reflective and systematic approach by sub-discipline, and with proposed designations.

In this model the four sub-disciplines could then also be linked directly to the four designations in which Product Design can be studied in the UK (as shown in Figure 5 above). If this model were to be adopted by universities then the content and approach of courses could be clearly communicated to potential students and consistency in the use of the different designations and course titles be achieved. 


\section{APPLICATION IN EDUCATION}

At Buckinghamshire New University there are currently four degrees which are involved with the design of products; a BA degree in 'Product Design - Interior Product', BA and BSc degrees in 'Product Design', and a BEng degree in 'Engineering Design'. The BA degrees can trace their development back through the design crafts tradition at the university, whereas the BEng and BSc courses owe much more to the old engineering school. When next rewriting the courses the model which has been developed in this paper will be used to guide their design in order to give more clarity of the differences between the different courses to prospective students. Wider adoption of the model in academia in the UK would ensure clarity of the use of the different designations and degree titles for all prospective students.

\section{RELATION TO ACCREDITATION}

The model has a clear midpoint between the courses which are more closely related to applied arts and crafts (which utilise more reflective thinking and those which are more closely related to engineering and technology (which utilise more systematic thinking). For the purposes of professional body accreditation, consistency in the use degree title and designation across the courses in the UK would make it clear which courses are suitable for Registered Product Designer/Chartered Technical Product Design (RProdDes/CTPD) and Integrated Engineer/Chartered Engineer (IEng/CEng). The first two; 'BA/MA Design Crafts' and 'BDes/MDes Industrial Design' being suitable for RProdDes/CTPD, and 'BSc/MSc Design Engineering' and 'BEng/MEng Engineering Design' being suitable for IEng/CEng.

\section{CONCLUSION}

The research presented in this paper proposes a model of the most common sub-disciplines of the field of Product Design that are delivered in degree courses in the UK and proposes a model which could be used to differentiate them based upon the proportion of intuitive and systematic thinking present in each of them. If this model were to be adopted across universities which deliver courses that involve the design of products it could provide greater clarity of content and approach for prospective students, and also enable more consistency in the use of different designations and course titles. Additionally, it could simplify accreditation paperwork for RProdDes/CTPD and IEng/CEng courses, specifically the mapping of subject benchmark statements to course outcomes against the published PSRB standards.

\section{REFERENCES}

[1] Ito, J. Design and Science, 2016. The Journal of Design and Science.

[2] DiscoverUni. Product Design courses in the UK: https://discoveruni.gov.uk/results/?subject_query=Product+Design\&institution_query=\&instituti on_query_search $=$ [Accessed on 2020, 29 January]

[3] Cambridge Dictionary. Product, n.d. Available: https://dictionary.cambridge.org/dictionary/english/product [Accessed on 2020, 29 January]

[4] Schön D. Designing: Rules, types and worlds, 1988. Design Studies, 9(3), 181-190.

[5] Mutlu M. \& Er A. Design Innovation: Historical and Theoretical Perspectives on Product Innovation by Design, 2003. 5th European Academy of Design Conference.

[6] Sathikh P. Mapping design curriculum in schools of design and schools of engineering: Where do the twains meet? 2013. ICoRD 2013.

[7] Kim K \& Lee K. Two Types of Design Approaches Regarding Industrial Design and Engineering Design in Product Design, 2010. INTERNATIONAL DESIGN CONFERENCE - DESIGN 2010.

[8] Dixon J. Design Engineering: Inventiveness, Analysis, and Decision Making, 1966. McGrawHill.

[9] Taura T. Creative Design Engineering: Introduction to an Interdisciplinary Approach. Elsevier.

[10] Eder W. \& Hosnedl S. Design Engineering: A Manual for Enhanced Creativity, 2007. CRC Press.

[11] Walter A. Designing for Emotion, 2011.

\section{ACKNOWLEDGEMENTS}

The research presented in this paper has been funded by the European Union's Horizon 2020 research and innovation programme under grant agreement number 820718, and is jointly funded by the European Commission and the Department of Science and Technology of India (DST). 